\title{
La renovación de los métodos docentes del derecho tras la reforma de la universidad europea*
}

\section{Isaac Tena Piazuelo ${ }^{*}$}

Resumen. En las universidades no siempre se ha enseñado lo mismo, ni tampoco se ha enseñado siempre del mismo modo. Los métodos para la enseñanza del derecho se adaptaron a lo largo de la historia, de manera más o menos espontánea. Sin embargo, un acontecimiento producido en la universidad europea hace una década determinó que los países que formaban parte del proceso de Convergencia en el Espacio Europeo de Educación Superior tuvieran que poner al día sus métodos de enseñanza. También la enseñanza del derecho, en particular, se ha renovado.

Palabras Clave: enseñanza del derecho, métodos, técnicas docentes, Espacio Europeo de Educación Superior.

\section{The Renewal of the Law Teaching Methods after the European Higher Education Reform}

ABSTRACT. Study programs at universities have never been exactly alike, neither the learning methods. Law teaching plans have been spontaneously adapted throughout history. Nevertheless, a decade ago, an occurring that involved the European Uni-

Fecha de recepción: 7 de abril de 2020. Fecha de aceptación: 24 de agosto de 2020. Para citar el artículo: Tena Pizuelo, I., "La renovación de los métodos docentes del derecho tras la reforma de la universidad europea", Revista de Derecho Privado, Universidad Externado de Colombia, n. ${ }^{\circ} 40$, enero-junio 2021, 515-544, Dor: https://doi.org/10.18601/01234366.n40.18.

** Universidad de Zaragoza, Zaragoza, España; catedrático de Derecho Civil. Academia Aragonesa de Jurisprudencia y Legislación, Zaragoza, España; académico de número. Doctor en Derecho de la Universidad de Zaragoza, Zaragoza, España. Contacto: itena@unizar.es Orcid: 0000-0001-64383475 . 
versities concluded by making those countries that were part of the process of convergence in the European Higher Education Area, update their learning methods. Therefore, Law teaching has also been renewed.

KEYwords: Law teaching, methods, teaching techniques, European Higher Education Area.

Sumario. Introducción. I. Significado de métodos y metodologías docentes. II. El "modelo Bolonia" y su trascendencia en el método docente. III. El concepto de aprendizaje durante toda la vida. IV. Métodos y metodologías docentes, en particular. v. Repertorio de metodologías docentes. Conclusiones. Referencias.

\section{Introducción}

No es probable que nadie pueda plantearse, siquiera, la duda de si el derecho se ha explicado siempre del mismo modo en las universidades. Con independencia de la mayor o menor estabilidad de los ordenamientos jurídicos, las técnicas de instrucción docente se han ido adaptando a los contenidos que se enseñan, también a un conjunto de factores esencialmente tan cambiantes como la historia. Al igual que ciertas percepciones sociales sobre la relación entre docentes y discentes, o los recursos de información disponibles, determinados avances técnicos, el marco legal de las carreras universitarias, etc. Sin embargo, en la universidad europea se ha producido en la última década un acontecimiento de carácter común, que inmediatamente afectaba a cuestiones de carácter político y formal (como la duración de los estudios universitarios en las distintas titulaciones reconocidas, o el sistema de créditos para grados y posgrados), pero que tiene otras muchas implicaciones. En efecto, el denominado proceso de Convergencia en el Espacio Europeo de Educación Superior (EEES), conocido usualmente y de manera sintética como "proceso de Bolonia" o "Plan Bolonia", también ha afectado la manera de enseñar. De modo que en este decenio precisamente ${ }^{1}$, quienes enseñamos derecho también hemos tenido que actualizar las técnicas o recursos que veníamos utilizando en épocas anteriores. Sin entrar ahora en aspectos que ya son historia, me gustaría referirme a esa innovación o renovación docente, desde la perspectiva de la enseñanza del derecho privado, y del derecho civil en particular. Un apunte final antes de entrar en materia. Es clásica la distinción entre "enseñar" e "investigar" (así como otra asimilable, entre "ciencia" y "técnica"), y tan cierta como que homines, dum docent, discunt. Cuando menos, la faceta docente o pedagógica es el signo distintivo de los profesores de derecho (o académicos) respecto de otros meritorios operadores jurídicos. No es menos cierto que durante bastante tiempo los sistemas de promoción profesional del

1 Las instancias europeas fijaron en 2010 el límite para que los países que suscribieron (en 1999) el acuerdo o declaración de Bolonia llevasen a cabo la convergencia de los estudios universitarios. 
sistema universitario han valorado poco la dedicación docente (aunque parezca un contrasentido), que no resulta fácilmente mensurable (como sí lo son los percentiles de publicaciones), ni especialmente productiva (sobre todo en las universidades públicas, que tienen una "clientela" asegurada por la subvención de las tasas académicas). Pero ahí mismo se está produciendo un cambio de sesgo, al aceptarse que no se puede lograr la excelencia académica (ni la institucional, ni la del profesorado) sin contar con modos excelentes de enseñar. Se trata de otra consecuencia de la reforma de Bolonia, que ha extendido a los estudiantes un papel protagonista en la universidad que antes correspondía casi en exclusiva al profesorado, y a las estructuras de gobierno y gestión académica.

\section{Significado de métodos y metodologías docentes}

Es bastante común que, en el ámbito universitario, se emplee la palabra "metodología" en referencia tanto a la docencia como a la investigación. Sin embargo, respetando otro criterio, personalmente prefiero "método" en vez de hablar de "metodología" (es decir, las "estrategias" para materializar un método ${ }^{2}$ ). Ya que este último concepto constituye la aplicación práctica de aquel otro, que tiene carácter categórico, alude a un repertorio de medios prácticos. Es decir, "método" es el objeto del modelo docente, y en ese sentido tiene algo de permanente. Mientras que la "metodología" es la técnica, o recursos técnicos concretos que se emplean para consumar el método, y en tal sentido es variable en su evolución (las técnicas se desechan, se innovan, etc.), y acomodaticia con respecto a las circunstancias concretas en las que se pretende enseñar.

El método y la metodología utilizados tanto en la investigación como en la docencia universitaria se han estudiado tradicionalmente desde diversas especializaciones científicas. Hoy en día constituyen un importante objeto de atención por parte de una rama floreciente de la investigación educativa especializada, con cuyas aportaciones hay que contar. Pero aunque la experiencia colectiva de lo previo constituye una ayuda valiosísima en la tarea de enseñar, debe reconocerse la importancia decisiva de las propias condiciones personales y aptitudes. Y en consecuencia (tampoco en el modo de enseñar) no es prudente tratar de establecer modelos apriorísticos, con exclusiva preferencia sobre los demás. De otro lado, en toda actividad docente y de investigación aparecen una serie de elementos o constantes (aunque sea variable su entidad, como distintos son los resultados que propician) que actúan determinándolas de una parecida manera: los elementos personales (el profesor, los alumnos) y materiales (medios de diverso tipo, instalaciones y espacios, recursos bibliográficos y técnicos, etc.), incluso circunstancias de orden legal (marco legal de la docencia universitaria, planes de estudios, titulaciones que se expiden, situaciones y categorías profesionales del profesorado), que todo docente e investigador debe tener

2 Las "metodologías docentes" también suelen denominarse "estrategias docentes". 
en cuenta de modo imprescindible, al margen de su propia versatilidad personal y capacidad de adaptación a unos y otras.

\section{El “modelo Bolonia” y su trascendencia en el método docente}

Escapa a mi propósito actual explicar con detalle (un fenómeno autónomo) la reforma del EEEs, aunque constituye el nuevo marco normativo (y también de la renovación de la metodología docente, como he dicho) de la universidad europea ${ }^{3}$. El proceso de Convergencia resulta un fenómeno poliédrico, con múltiples imbricaciones (no en vano, comporta una cierta "cosmovisión economicista"4).

La revolución pedagógica que supuso "Bolonia" ha sido sin duda extraordinaria: las metodologías docentes han tenido que adaptarse forzosa y (en ocasiones) forzadamente a los nuevos parámetros de enseñanza-aprendizaje (y también en la investigación) que exigía la "Europa del conocimiento" (como uno de los signos distintivos de la sociedad y la economía europeas) ${ }^{5}$. Pero su novedad puede relativizarse un tanto en mi país, especialmente en lo tocante a la enseñanza del derecho. Pues, a finales del siglo xIX, la Institución Libre de Enseñanza introdujo nuevos conceptos sobre docencia, en general, y sobre enseñanza universitaria del derecho, en particular, que pueden parangonarse con los del llamado "proceso de Bolonia" (con el que guardan gran semejanza en los medios y solamente parcial similitud en cuanto a los fines ${ }^{6}$ ).

3 Uno de los argumentos más críticos, pues apunta a lo que podríamos denominar la línea de flotación del modelo de universidad contenido en la Convergencia EEEs, a la propia idea de su ser como universitas scientiarum, es que se ha consumado el paso de la universidad del saber (ciencia) a la del conocer (información). Sin profundizar en lo anterior, tal vez convenga recordar las palabras de C. S. Lewis: “¿Dónde está la sabiduría que se nos ha perdido entre el conocimiento? ¿Dónde está el conocimiento que se nos ha perdido entre la información?".

Sobre la nueva tesitura que comporta la formación universitaria con miras al mercado laboral, véase Quintero Olivares, G., La enseñanza del derecho en la encrucijada. Derecho académico, docencia universitaria y mundo profesional, Madrid, Cuadernos Civitas, Thomson Reuters, 2010, 29.

4 BaLdus, Ch., "Calidad: ¿para qué, para quién? Una perspectiva alemana y continental sobre el llamado proceso de Bolonia”, El Cronista del Estado Social y Democrático de Derecho, n. ${ }^{\circ}$ 4, 2009, 14.

5 Resulta esclarecedora la lectura de la "Comunicación de la Comisión de 5 de febrero de 2003: El papel de las universidades en la Europa del conocimiento" (Сом (2003) 58 final - no publicada en el Diario Oficial), [en línea], disponible en: https://eur-lex.europa.eu/legal-content/ES/ TXT/?uri=LEGISSUM\%3Ac11067 [consultado el 12 de enero de 2020].

Es cierto que con Bolonia la universidad ha cambiado. Pero a menudo se nos escapa que, en realidad, es la propia sociedad (en términos no solamente nacionales) la que previamente ha experimentado cambios bien profundos. Martínez Martín, M., "La universidad en la sociedad contemporánea”, en Laudo, X. y Vilafranca, I. (coords.), ¿Enseñar y aprender en la universidad? Ensayos fenomenológicos y hermenéuticos, Barcelona, Universidad de Barcelona, 2016, 10.

6 "Resumen" de Cavanillas Múgica, S., "La enseñanza del derecho según la 'Institución Libre de Enseñanza", Revista de Educación y Derecho, n. ${ }^{\circ} 11$ (dedicado a: Modelos de clínicas jurídicas en España), 2015, 1-20, y en particular cfr. p. 3: “A finales del siglo XIX las Facultades de Derecho fueron protagonistas y precursoras de un movimiento de renovación pedagógica -el de la llamada 'Institución Libre de Enseñanza' [...]- cuya influencia, en los niveles no universitarios, llega hasta nuestros días. La pedagogía española nació en las Facultades de Derecho”. 
No cabe duda de que en la pedagogía universitaria instaurada tras la Convergencia europea se ha producido una importante alteración de algunos paradigmas tradicionales sobre la formación de los estudiantes. ¿Qué es lo que el profesor puede exigir realmente a sus alumnos? ¿El denostado virtuosismo de la memoria? Ya no, al menos en la teoría del sistema "Bolonia". Es ahí donde la nueva terminología intenta justificar su utilidad: el estudiante no necesita retener (al menos en la medida en que antes se exigía poseer un cierto volumen de conocimientos, materialmente almacenados en la memoria) lo que con facilidad puede obtener a través de los recursos modernos de información y documentación. El cometido del profesor es propiciar con sus alumnos la adquisición de competencias, generales y específicas, y el desarrollo de destrezas.

Lo que a su vez provoca, necesariamente, otra evolución en los sistemas para evaluar a los estudiantes. La generalidad de los medios que (antes de Bolonia) venían utilizándose, conducían a un "modelo" distinto de estudiante, pues se primaba ante todo (con el reconocimiento de una nota o calificación) su capacidad para memorizar datos y reglas (lo que se conoce como "información funcional"7) y la habilidad para realizar -valiéndose de ellos- determinados procesos de razonamiento jurídico (es decir, un "objetivo conductual", en que se aprovecha especialmente el "pensamiento formal" por el alumno ${ }^{8}$ ).

Debido a los nuevos criterios de método docente, la formación universitaria que en la actualidad perseguimos no va a consistir ya en la mera asistencia a clase (ya fueran clases teóricas o prácticas, constituía la actividad principal de los estudiantes durante décadas $)^{9}$. Lo que a su vez ha propiciado una reducción de las horas de clase presencial (aunque sea compatible con que el estudiante deba pasar más tiempo en la universidad del que antes dedicaba a la asistencia a clase). Y en que los alumnos deban abandonar la actitud pasiva de quien se limita acríticamente a recibir información, de manera unilateral, desde el punto de vista exclusivo de sus profesores. Justamente esos cambios de concepto de la formación académica se complementan con las novedades introducidas en el ámbito de la evaluación de conocimientos, puesto que ahora se apuesta por sistemas de evaluación continua o continuada. Y, al tiempo,

7 BERNAD, J. A., Estrategias de enseñanza-aprendizaje en la universidad, Zaragoza, Universidad de Zaragoza, 1991, 55.

8 Ibíd., 56.

9 No es así, pues la novedad es la incorporación activa del estudiante al proceso pedagógico, que vislumbra lo que iba a deparar la reforma de Bolonia desde el punto de vista de las metodologías docentes, las cuales se califican de activas y colaborativas. Y se proponía al respecto: "Implantar sistemas de aprendizaje en los que el alumno no es un mero receptor de un corpus de conocimientos establecido, sino un agente activo que, enfrentado a tareas, casos y problemas concretos, construye su propio conocimiento activamente, analizando situaciones, buscando soluciones, revisando teorías y posiciones de especialistas, construyendo sus propios marcos conceptuales o revisándolos a la luz de nuevas aportaciones o experiencias". Universidad de Zaragoza, Programa de Mejora e Innovación de la Docencia (En el marco de la Convergencia al Espacio Europeo de Educación Superior), Zaragoza, Instituto de Ciencias de la Educación y vicerrectorados de Ordenación Académica y de Estudiantes, 2004, 18. 
la mayor autonomía personal que se exigirá al estudiante universitario se relaciona con una valoración de las nuevas tecnologías de información y comunicación (TICs).

En suma, la formación universitaria no debe ir encaminada solamente a suministrar contenidos teóricos o prácticos, es decir, "conocimientos". Sino también "competencias", y "destrezas" para los futuros profesionales universitarios ${ }^{10}$. Se ha producido un importantísimo cambio de sesgo en el planteamiento docente: el alumno ha pasado a ocupar un papel protagonista (en algunas ocasiones, incluso próximo al de "cliente") que antes correspondía en casi total medida al profesor y su enseñan$\mathrm{za}^{11}$. Tampoco es algo completamente extraño a nuestra tradición. Un planteamiento semejante, en torno al estudiante, se sustentó muy a principios del pasado siglo en la "Institución Libre de Enseñanza" 12.

En el marco de una nueva relación docente, entre el profesor y el alumno, aunque las clases magistrales no lleguen a desparecer por completo, en la teoría deberían ser gradualmente sustituidas por procedimientos heurísticos de formación. Todo ello comporta una nueva definición del papel y funciones del profesor universitario ${ }^{13}$.

10 Precisamente la noción de "competencias" constituye uno de los ejes del nuevo modelo de enseñanza tipo "Bolonia", y ha dado origen a una bibliografía muy amplia (sobre todo por parte de los especialistas en educación). No resulta fácil de definir, pues responde a múltiples descripciones. Al respecto, véase CANO GARCíA, M. 'E., "La evaluación por competencias en la educación superior", Profesorado. Revista de Currículum y Formación de Profesorado, vol. 12, n. . 3, 2008, 1-16, en particular pp. 4 y ss. Entre otras muchas posibilidades de definición, en sentido general las competencias consisten en un "[s]aber hacer complejo que exige un conjunto de conocimientos, habilidades, actitudes, valores y virtudes que garantizan la bondad y eficiencia de un ejercicio profesional responsable y excelente". Y en un sentido específico: "Las competencias profesionales definen el ejercicio eficaz de las capacidades que permiten el desempeño de una ocupación, respecto a los niveles requeridos en el empleo. Es algo más que el conocimiento técnico que hace referencia al saber y al saber-hacer. El concepto de competencia engloba no sólo las capacidades requeridas para el ejercicio de una actividad profesional sino también un conjunto de comportamientos, facultad de análisis, toma de decisiones, transmisión de información, etc., considerados necesarios para el pleno desempeño de la ocupación". Igualmente interesante Rivera Ayala, L. A., "Cinco competencias genéricas clave en los estudios de derecho", Revista de Educación y Derecho, n. ${ }^{\circ}$ 11, 2015, 1-19. El concepto de "destrezas" se refiere a la eficiencia para ejecutar una determinada tarea.

11 Los expertos en educación advierten de los límites de ese equilibrio entre alumnos y profesores, insistiendo en que se trata necesariamente de una "relación asimétrica", pues el proceso educativo requiere que los alumnos perciban esa relativa falta de igualdad. Martínez Martín, M., "La universidad en la sociedad contemporánea", cit., 10-11. Me atrevo a expresar la misma idea con otras palabras: la empatía y el respeto mutuo entre profesores y estudiantes no tienen que ver con un "colegueo" inapropiado para los fines de la relación docente.

12 “Adelantándose más de cien años a la formulación de uno de los conocidos pilares de la llamada 'reforma de Bolonia', afirma Giner de los Ríos (1902) que 'el estudiante, no el maestro, es el primer elemento de la universidad"”. Cavanillas Múgica, S., "La enseñanza del derecho según la 'Institución Libre de Enseñanza", cit., 9-10.

Se trató de un proyecto pedagógico, de gran influencia intelectual y política, que se desarrolló entre 1876 y 1936 . No es vana la coincidencia con algunas ideas del notable filósofo Ortega y Gasset, pues él mismo se destacó en la defensa de la institución.

13 Se ha producido una reconfiguración del papel del profesor en el proceso docente. Aunque queramos creer que no pierde importancia, se destaca su misión como facilitador del nuevo protagonismo que adquiere el estudiante: "Nuevo rol del profesorado. Se produce una redefinición del papel del profesorado haciéndolo actor de las metodologías activas y colaborativas que se pretende implantar. 
Trae consigo el desarrollo de nuevos roles y tareas que no pueden considerarse como meramente "docentes" (en el sentido tradicional del término) ${ }^{14}$ : la concepción del profesor como facilitador ("hacer fácil lo difícil") del aprendizaje del alumno; la concepción del profesor como mediador entre la disciplina y los estudiantes ${ }^{15}$; las nuevas funciones de orientador y guía en la búsqueda, apoyo y sustento en el esfuerzo; de creador y gestor de las condiciones y experiencias de aprendizaje; de certificador y juez de resultados; de modelo y tutor personal, profesional y académico. Las tareas fundamentales del profesor deben estar orientadas a: enseñar al alumno a "aprender a aprender"; desarrollar su autonomía personal; fomentar el pensamiento crítico y la reflexión sobre su proceso de aprender.

Creo que debo adelantar una reflexión valorativa un tanto descarnada, quiero decir, llena de necesaria subjetividad ${ }^{16}$. Con esta explicación breve (pues hemos asistido, con "Bolonia", al descubrimiento un mar de novedades que no parece tener orillas ${ }^{17}$ ) es comprensible que método y metodologías docentes, tan novedosos,

Por supuesto, el profesorado sigue teniendo un papel fundamental en el diseño del trayecto del estudiante (diseño curricular), aunque ahora entendido más como una sucesión de experiencias de aprendizaje que como la organización sucesiva de un conjunto de contenidos. La calidad del trabajo docente tiene mucho que ver con la calidad y relevancia de esas experiencias de aprendizaje que el profesor propone a sus alumnos. En ese marco, la tarea asignada al profesor tiene que ver fundamentalmente con orientar, impulsar y respaldar el trabajo del alumno y hacerlo en situaciones de pequeños grupos tutorizados o de tutorías individualizadas más que en grandes grupos. Igualmente, se hace imprescindible que el profesor diseñe un sistema apropiado para que el estudiante pueda evaluar en cada momento la evolución y adecuación de su trabajo (la percepción del propio aprendizaje constituye uno de los motores más poderosos de motivación)". UNIVERSIDAD DE ZARAGOZA, Programa de Mejora e Innovación de la Docencia, cit., 19.

14 De la CRUZ, M. a Á., La concepción del profesor como mediador entre la disciplina y los estudiantes, Zaragoza, Instituto de Ciencias de la Educación Universidad de Zaragoza, Colección Documentos, n. ${ }^{\circ}$ 2, 2005, 35-66; LóPEZ-Sidro, Á., "Reflexiones sobre los desafíos de Bolonia y la misión del profesor universitario. Entre la innovación y la tradición", Revista Jurídica de Investigación e Innovación Educativa, n. ${ }^{\circ}$ 4, 2011, 23-44.

15 De la Cruz, M. a A., La concepción del profesor como mediador entre la disciplina y los estudiantes, cit.

En realidad, cuando se centra el enfoque del proceso educativo en el alumno no estamos simplemente ante una característica revalorizada de esa formación. Se trata de algo más, de un verdadero paradigma del proceso de renovación pedagógica, que tiene su propia denominación terminológica ("aprendizaje centrado en el estudiante", que admite variantes) y su propio aparataje bibliográfico. Para diferenciar aquel nuevo paradigma en la concepción de la enseñanza en general, del anterior que se centraba en el papel del profesor, resulta muy ilustrativo el cuadro de comparación que ofrecen Tourón, J., Santiago, R. y Díez, A., "The Flipped Classroom”. Cómo convertir la escuela en un espacio de aprendizaje, Barcelona, Digital Text, 2014, 5-6.

16 Pienso que tengo cierta legitimidad, en virtud de alguna de las características de mi propio currículo. Durante una década, que precisamente coincide con la parte sustancial del proceso de Convergencia en el EEEs, he tomado parte en la gestión académica de mi facultad, lo que me ha permitido recibir de primera mano las reacciones a su implantación concreta. Pienso que se combinaron, en medida variable, los mismos entusiasmos y desalientos que condujeron a la (necesaria) puesta en marcha del nuevo modelo docente.

17 Me parece que no exagero si afirmo que el vademécum terminológico nunca está del todo actualizado, cada día puede incluirse una actividad que se da por definitivamente inventada o descubierta 
hayan provocado un cierto desconcierto entre los profesores con más experiencia docente, y tal vez algún asomo de desánimo ante las nuevas tareas (mejor aún, el nuevo estatuto de cometidos que sin mayor mediación se les han encomendado $)^{18}$. De ser así, no es bueno. Es importante considerar las necesidades del estudiante, y lo que la sociedad demanda en su formación, pero también pienso que no puede haber una buena universidad sin buenos profesores ${ }^{19}$. Y lo cierto es que, en ocasiones, el mayor énfasis en aquellas necesidades ha supuesto un descuido de la atención que también hay que dispensar al profesor.

\section{El concepto de aprendizaje durante toda la vida}

El credo paneuropeo contemporáneo ha alumbrado un ámbito cultural, social y económico propios - sin exageración, una nueva ciudadanía-. Para comprobarlo bastaría con repasar los principios constitutivos del mercado único europeo (como la libre circulación, y establecimiento, de profesionales en la Unión Europea), o la dimensión colectiva de Bolonia como standard europeo frente al modelo económico, social y educativo norteamericano. Sin olvidar el concepto de "Europa del conocimiento", como base de su desarrollo económico y social. En relación con estas cuestiones hay un aspecto instrumental al que todavía no se ha prestado demasiada atención en la práctica, hasta este momento. Se trata del "Suplemento europeo al Título" $\left(\mathrm{SET}^{20}\right.$ ) (Diploma Suplement, DS), que tiene -para empezar- una dimensión administrativa. Pues supone detallar (materialmente en el expediente académico de

cuando por fin puede asignarse un término para su denominación (por lo general, en inglés). Luego lo veremos, al tratar de las metodologías más en uso en las facultades de derecho.

18 Lo que, de manera correlativa, a su vez permite entender por qué la dicotomía docencia-investigación todavía se resiste a desaparecer por completo. Por si fuera posible una dedicación universitaria que pudiera refugiarse en la investigación, a salvo de las exigencias abrumadoras de la actividad docente propiamente dicha.

Realmente punzante (y creo que injusta, por excesiva) resulta la interpretación de NúÑEZ, C. E., Universidad y ciencia en España. Claves de un fracaso y vías de solución Madrid, Gadir, 2013, 276: "Quienes no tenían mucho que hacer y carecían de verdadera vocación universitaria acogieron Bolonia con entusiasmo, ya que les permitía ampliar sus méritos de gestión con vistas a una promoción; los demás, minoría silenciosa, asistieron descorazonados a este nuevo envite contra la verdadera esencia de la universidad".

19 Coincido con NúÑEZ, C. E., Universidad y ciencia en España, cit., 41: "Ningún centro educativo, ninguna escuela o universidad será nunca mejor de lo que lo sean sus profesores".

20 En mi país se reguló mediante el Real Decreto 1044/2003, de 1 de agosto, por el que se establece el procedimiento para la expedición por las universidades del Suplemento Europeo al Título (publicado en Boletín Oficial del Estado, 11-09-2003). El Suplemento es el documento que acompaña a cada título universitario, con la información unificada para toda Europa, sobre los estudios cursados, los resultados obtenidos, las capacidades profesionales adquiridas y el nivel de su titulación en el sistema nacional de educación superior. Concretamente, debe detallar para cada universitario: datos del estudiante, información de la titulación, información sobre el nivel de la titulación, información sobre el contenido y los resultados obtenidos, información sobre la función de la titulación, información adicional, certificación del suplemento e información sobre el sistema nacional de educación superior. 
cada alumno) en un formato común en todo el EEEs, las competencias adquiridas por los estudiantes con los estudios universitarios y una precisa explicación de las asignaturas cursadas, y su dimensión en términos del ECTs (European Credit Transfer and Accumulation System). Pero, al margen de ese aspecto de carácter burocrático, son más importantes las intenciones u objetivos de lo que coloquialmente se conoce como "mochila académica". Es decir, lo que gráficamente se dibuja como una especie de petate, con el que cada universitario iría recorriendo el sistema de formación superior comunitario, no solamente la que tiene carácter inicial, sino igualmente la formación continua o continuada a la que se aspira. Es decir, aprendizaje permanente (lifelong learning) ${ }^{21}$. Este nuevo ámbito que se abre en la formación resulta muy importante para la universidad, que tiene que dejar de identificarse como una etapa de juventud (por lo general), en que se adquiere la preparación que posibilita el acceso al mercado profesional. Ahora, en correspondencia con el dinamismo de ese mercado, y la movilidad profesional (en diferentes sentidos), la universidad puede proporcionar parte de esa formación que -se supone- cada universitario (titulado o no) estará en situación de recibir hasta que concluya su vida profesional.

\section{Métodos y metodologías docentes, en particular}

No voy a volver sobre la distinción entre método y metodologías, pues lo que importa ahora es que intente explicar de qué medios auxiliares o herramientas docentes puede valerse el profesor universitario (en particular, el que explique derecho positivo). Si, tal como se viene diciendo, la tarea docente consiste en transmitir unos instrumentos, el primero de ellos ha de ser la programación de la materia a enseñar según criterios de unidad conceptual y de asignación del período docente con el que se cuenta (aunque la diversidad de materias, y el modo de ordenarlas, entiendo que me dispensan de ocuparme de este aspecto contingente).

Habré de detenerme ahora en los medios usuales para la enseñanza del derecho (del civil, en particular). Recordaré algunos instrumentos tradicionalmente utilizados -no todo ha cambiado- que siguen valiendo para ese propósito. Aunque los nuevos parámetros de la docencia según el "Modelo Bolonia" y también los avances técnicos, y su disponibilidad, faciliten actualmente una oferta muy amplia de posibilidades, más novedosas, a las que debo referirme.

¿Cómo enseñar? Para empezar, no cabe duda de que el profesor universitario debe conocer o dominar la materia que enseña a sus alumnos. Pero, cuando lo in-

21 En abril de 2008 el Consejo Europeo y el Parlamento Europeo aprobaron el denominado Marco Europeo de Cualificaciones para el Aprendizaje Permanente (EQF-MEC). El EQF es una recomendación a los Estados miembros y establecía el año 2010 como fecha límite para que los países realizasen los ajustes entre sus sistemas de cualificaciones y el EQF, y el año 2012 como fecha de aplicación completa. El EQF es una herramienta para fomentar el llamado aprendizaje permanente. Su objetivo es vincular los diferentes sistemas nacionales de cualificaciones mediante ocho niveles de referencia comunes a toda Europa y que abarcan desde los certificados de educación escolar hasta el doctorado. 
tenta, la siguiente cuestión -en nada exenta de dificultad- es qué camino seguir para lograr esa transmisión de conocimientos ${ }^{22}$. No puede perseguirse un método universalmente idóneo, sencillamente porque no lo hay, ni para enseñar el derecho ni tampoco otras ramas de la ciencia ${ }^{23}$. Sí puede formularse sin embargo una taxonomía, estableciendo dos grandes métodos didácticos del profesorado universitario: el método "heurístico" y el método "magistral"; aunque la evaluación de estas posibilidades sea solamente orientativa, pues, como afirma Bernad, lo que ha de buscar el profesor universitario es un "método personal", como condición necesaria para garantizar mínimos de eficacia ${ }^{24}$.

El método "magistral", cuando se da en su estado puro, consiste en imponer al alumno lo que debe aprender sin apenas prestar atención al proceso, a los medios o a la estrategia por los cuales aquello puede lograrse. Se trata en definitiva de un sistema imperfecto, pues se basa en el equívoco de que todos los alumnos utilizan las mismas estrategias de aprendizaje, y el papel del alumno prácticamente se limita a acoger el mensaje del profesor, tal como este lo ofrece, para repetirlo en el examen: "la enseñanza bascula prioritariamente sobre la actividad del docente en cuanto informador y juez final del rendimiento de sus alumnos" 25 .

Frente al método anteriormente descrito (al que se opone), el método "heurístico" de enseñanza tiende a orientar el proceso de aprendizaje del alumno mediante directrices, que presentan los contenidos de forma que le faciliten compaginar lo que tiene que aprender con sus capacidades para aprenderlo. "Este método se fundamenta en el paradigma cognitivo, según el cual el alumno es un ser activo, que codifica subjetivamente los estímulos recibidos hasta integrarlos significativamente en sus estructuras previas de conocimiento" 26 .

Aunque las taxonomías son menos importantes que sus contenidos, la categoría del método heurístico resulta sumamente amplia (a modo de cajón de sastre en donde, por exclusión, se sitúan todos los métodos que no son magistrales), puede acoger incluso algunas modalidades que luego veremos dentro del epígrafe "la clase práctica". Y, a su vez, en dicho epígrafe trataré de técnicas (como la del "caso") que, aunque se las llame con frecuencia "métodos", son propiamente "metodologías" que forman parte del método heurístico.

Planteadas así las posibilidades, parecería que el segundo de los métodos expuestos fuese el ideal de enseñanza ${ }^{27}$, mientras que el "magistral” sería una práctica

Creo que era Cicerón quien afirmaba que una cosa es saber y otra saber enseñar.

23 BERnAD, J. A., Estrategias de enseñanza-aprendizaje en la Universidad, cit., 47-48.

24 Ibíd., 52.

25 Ibíd., 48-49.

26 Ibíd., 56 y 49.

27 No necesariamente esa percepción tiene carácter absoluto: SchuH, J. E., "Bolonia y la enseñanza del derecho", El Cronista del Estado Social y Democrático de Derecho, n. . 5, 2009 y Schuн, J. E., "Heurística: la chapuza del derecho", en García AmAdo, J. A., Razonar sobre derechos, Valencia, Tirant lo Blanch, 2016, 333-347. 
que se debería desterrar. Sin embargo ya he dicho que en el fondo lo que el profesor debe lograr es una adaptación o conciliación de las características básicas de los modelos docentes a las particulares circunstancias en que él enseña. Convivencia de "lo viejo" con otros modelos tan novedosos que todavía están enunciándose por los estudiosos en la teoría de la educación.

\section{Repertorio de metodologías docentes}

Si se acepta la diferenciación, en el fondo propedéutica, entre método y metodología es preciso examinar ahora los instrumentos formales mediante los que se lleva a cabo la enseñanza del derecho. El mapa conceptual que pueda elaborarse difícilmente puede tener carácter cerrado, pues la oferta de posibilidades es sumamente amplia ${ }^{28}$, y con muy estrecha frecuencia los especialistas en pedagogía general (y también los profesores, en el ejercicio de sus respectivas especialidades) elaboran tal vez un nuevo término para describir una nueva actividad docente, o incluso una variante de la misma ${ }^{29}$. Pienso que, gracias a lo que supuso la revolución de la Convergencia EEES, y el interés creciente hacia nuevas propuestas pedagógicas y metodológicas, hemos asistido a la conformación de una nueva disciplina autónoma: una suerte de "metametodología docente" en la formación universitaria. Una "metodología de la metodología en la docencia”, y también en la investigación.

\section{A. La clase magistral}

La técnica magistral no es nueva, aparece en los orígenes de la universidad, siendo antecedente suyo la técnica medieval de la lectio o lectura-comentario de un texto escogido como base de un curso ${ }^{30}$. El fundamento didáctico de la lección se basa en una acumulación de saber por parte del profesor y su transmisión a los alumnos mediante la comunicación oral. Desde aquí mismo, cabría cuestionar si un procedimiento docente, tan útil durante siglos, ha dejado de serlo. Especialmente, si "Bolonia" lo ha periclitado, pues no en vano suele aceptarse que en los aspectos

28 Aguado, I., Barrutia, J. M. a y Etxebarria, C., "Los estudios de casos como instrumento de innovación educativa en la enseñanza universitaria”, en Elejalde García, M. ' J. y Pereira, J. A. (eds.), Los grados universitarios: posibilidades y caminos de innovación, Bilbao, Universidad del País Vasco, 2014, 110.

29 "Las metodologías educativas suelen girar alrededor de las teorías del aprendizaje (basadas en la psicopedagogía), como son el conductismo, el cognitivismo, el constructivismo y últimamente el conectivismo. Cada paradigma tiene sus procesos, actividades y métodos de actuación”. FidaLGo, Á., "Metodologías educativas-innovación educativa. Conceptos, recursos y reflexión sobre innovación educativa", [en línea], disponible en: https://innovacioneducativa.wordpress.com/2007/10/08/ metodologias-educativas [consultado el 12 de enero de 2020].

30 Capella Hernández, J. R., El aprendizaje del aprendizaje, 2. a ed., Madrid, Trotta, 1998, 25 ss.; EsteBAN BARA, F., "Vuelta al pasado de la universidad para repensar su futuro", en LAUDO, X. y VILAFRANCA, I. (coords.), ¿Enseñar y aprender en la universidad? Ensayos fenomenológicos y hermenéuticos, Barcelona, Universidad de Barcelona, 2016, 142-143. 
metodológicos aquel proceso supuso el tránsito de un modelo de enseñanza a un modelo de aprendizaje ${ }^{31}$.

Por más que la propia expresión "clase magistral" algunas veces se utilice en sentido irónico y peyorativo, como referencia a un modelo docente superado y poco participativo, sigue siendo -al menos en lo que a las asignaturas jurídicas tradicionales respecta- un medio fundamental en la enseñanza del derecho ${ }^{32}$. Calificarlo como "medio principal" depende de la orientación que quiera darle el profesor, según cómo ordene la programación de objetivos y los medios para lograrlos.

En mi opinión, sin perjuicio de que es preciso que la práctica jurídica tenga un creciente protagonismo en los planes de estudio, la "clase teórica" (término más consonante con el signo de un tiempo poco dado a seguir maestros) es la base sobre la cual se construye la programación de los procesos destinados a enseñar el derecho. Bien entendido que me refiero a un modelo de relación docente -la clase magistral- que habrá que mantener alejado de sus propios vicios: como la aridez de las explicaciones, el escaso recurso a medios gráficos o audiovisuales, la falta de aprovechamiento de la técnica de la ejemplificación, el auxilio excesivo de un determinado manual durante la clase, o que esta consista en un monólogo pronunciado sin contemplar el proceso de comprensión por parte de la audiencia, etc. ${ }^{33}$.

A veces tiende a descuidarse que una de las razones del descrédito de la clase teórica (que, invariablemente, suele achacarse al profesor) se refiere propiamente a la actitud del alumno, que de una manera explícita adopta una postura pasiva ante lo que el profesor va diciendo: no suele preguntar, no solamente lo que podría provocarle curiosidad, sino ni tan siquiera lo que no ha entendido o lo que ha comprendido mal; asume por propia iniciativa la encomienda de amanuense $e^{34}$, pareciendo su pro-

31 GonzÁlez Rus, J. J., "Reflexiones sobre el futuro de la enseñanza del derecho y sobre la enseñanza del derecho en el futuro", Revista Electrónica de Ciencia Penal y Criminología, n. ${ }^{\circ}$ 5, 2003, 1-21.

32 En general sobre la utilidad de este método docente, véase ZuRiTA MARTín, I., "La lección magistral", en SÁnchez GonzÁlez, M. ${ }^{a}$ P. (coord.), Técnicas docentes y sistemas de evaluación en educación superior, Madrid, Narcea, 2010, 17-22.

La lección magistral, como modelo, puede admitir variantes; véase SAHUQuillo Matero, P. M. y SARria Chust, B., "La lección magistral participativa", en GARgallo LóPEz, B., Enseñanza centrada en el aprendizaje y diseño por competencias en la Universidad: fundamentación, procedimientos y evidencias de aplicación e investigación, Valencia, Tirant lo Blanch, 2017, 63-78.

33 En algún momento ha tenido cierto éxito un libro de BAIN, K., Lo que hacen los mejores profesores de universidad, Valencia, Universidad de Valencia, 2007. El autor se ocupa, muy brevemente, es verdad, de cuestiones clave en la instrucción docente: ¿cómo preparan las clases?, ¿qué esperan de sus estudiantes?, ¿cómo dirigen la clase?, ¿cómo tratan a sus estudiantes?, ¿cómo evalúan a sus estudiantes y a sí mismos? También resulta interesante Petschen, S., El arte de dar clases. Experiencias de los autores de libros de memorias, Madrid, Plaza y Valdés, 2013.

34 Aunque cada vez más se hayan sustituido la estilográfica y el "boli" por modernas herramientas informáticas. Que no solamente permiten transcribir las explicaciones de clase, tienen muchas más posibilidades: se pueden actualizar las primeras notas, corregir errores, incorporar informaciones complementarias, esos apuntes se pueden difundir o transmitir (sin que la grafía ajena suponga ya un problema), etc. Incluso suele olvidársenos algo muy importante: esos nuevos dispositivos con que los estudiantes asisten a clase pueden recoger imagen y sonido, normalmente de manera imper- 
pósito, más que el entender las nociones y saber estructurar el desarrollo de un tema, registrar gráficamente el curso de la clase.

\section{B. La clase práctica}

Uno de los tópicos con que se enfrentaba la actividad docente antes de la reforma propiciada por el "Modelo de Bolonia" era la falta de experiencias prácticas que se ofrecían a los alumnos. Lo que se suponía como un abuso de la formación teórica, y una desconexión con los conocimientos operativos que requería - de verdad- el mercado de trabajo. La crítica (que en todo caso existía, de parte del alumnado y de algunos sectores privados profesionales) era, aunque molesta para quienes nos dedicábamos al ejercicio docente, formalmente justa si nos atenemos a las previsiones de los viejos planes de estudios. En la actualidad todo ha cambiado (al menos sobre el papel), puede afirmarse que las prácticas se han revalorizado de diversas maneras ${ }^{35}$. Las "prácticas" son -ante todo- medios o instrumentos en la labor docente, pues permiten insistir en la formación (y propiciar las consabidas competencias y destrezas) del alumno, desde una perspectiva distinta (y complementaria) a la que proporcionan las clases teóricas. Lo que no pueden constituir, pues por ahora resulta imposible atender a las diversas orientaciones profesionales de los alumnos, es una ocasión para comenzar a adquirir conocimientos específicos (competencias y destrezas específicas) del concreto ejercicio profesional que se pretenda: de ser así habríamos de saber y poder dirigir clases prácticas para futuros abogados, para jueces y fiscales, o prácticas notariales, prácticas del registrador, prácticas del funcionariado más técnico, etc. Habiendo declarado la confianza que deposito en tales tipos de clases, he de insistir diciendo que aunque considero que no puede desperdiciarse la utilidad de las prácticas, estas deben estar en función de las clases teóricas, aunque fuera por la simple lógica de que no se puede poner en práctica lo que se desconoce. Y aun el propio alumno puede experimentar la utilidad de lo que se le ha explicado, cuando comprueba que permite resolver satisfactoriamente los problemas de tipo práctico que se le plantean. Son ocasión de insistir en lo que previamente ha podido enseñar el profesor a sus discípulos, y de una manera especial favorecen el hábito de utilizar

ceptible (dependiendo de la propia habilidad del usuario de tales adelantos), lo que nos abocaría a consideraciones de muy diverso tipo (como el respeto de la propiedad intelectual del profesor).

35 Ténganse en cuenta Diéguez Oliva, R., "Implantación experimental de alguna de las técnicas de los acuerdos de la Declaración de Bolonia en la titulación de derecho, en especial, derecho civil III: derechos reales y registro de la propiedad", en RodríGuez OrTEGA, N. (coord.), Acción tutorial, reflexión y práctica: una experiencia de interacción docente en la Universidad de Málaga, Málaga, uma, 2008, 153-158; Torrubia Chalmeta, B., "El aprendizaje práctico del derecho en un espacio virtual", Docencia y Derecho, n. ${ }^{\circ}$ 5, 2012, 1-11; Recio Ramírez, M. a Á., "El aprendizaje basado en la resolución de problemas: una experiencia práctica", Docencia y Derecho, n. ${ }^{\circ}$ 7, 2013, 1-8; DE LA PeÑa Amorós, M. ${ }^{a}$ M., "La evaluación de las prácticas en el grado en Derecho", Revista de Educación y Derecho, n. ${ }^{\circ}$ 10, 2014, 1-22; Marrades Puig, A. I., "Innovación educativa en las clases de derecho constitucional I a través de las actividades aplicadas y complementarias", Revista General de Derecho Constitucional, n. ${ }^{\circ}$ 21, 2015. 
razonamientos y argumentos lógico-jurídicos, familiarizando con la utilización de las "herramientas jurídicas" (publicaciones científicas, textos legales, bases de datos -tanto en soporte documental como informatizado- jurisprudenciales).

Supuesta la importancia de las clases prácticas en general, se plantea el ulterior problema de determinar su contenido, en qué hayan de consistir. También en cuanto a esto cabe una multiplicidad de posibilidades, con tanta variedad como pueda imaginarse: resulta tradicional que consistan en una aplicación del "método del caso" (aunque ahora son aprovechables determinadas posibilidades técnicas audiovisuales, o para examinar el soporte de actos judiciales o arbitrales, incluso se ha desarrollado el trabajo en clase con "cine jurídico", etc.), pueden consistir en un ejercicio de crítica de sentencias, resoluciones o normas de derecho positivo, cabe el recurso a la técnica de la "dramatización" de situaciones jurídicas, o incluso a la realización de actos jurídicos de la vida real (v.gr., celebración de contratos de compraventa -de pequeña entidad-para comprobar el cumplimiento de las condiciones contractuales, o verificar las consecuencias de la aceptación por correspondencia, o las responsabilidades de las partes contratantes, etc.), o la asistencia presencial a las sesiones de juicios, visita a registros y otros organismos jurídicos, etc.

\section{El método del caso}

Tal como he comentado, las prácticas pueden tener un objeto muy diverso (desde el momento que podríamos entender que lo son, en términos difusos, todas aquellas actividades con grupos docentes que se desarrollan al margen de las clases teóricas). Sin embargo, dentro de esa amplia variedad de posibilidades hay algunas que resultan especialmente naturales a las asignaturas de derecho positivo. Tal es el caso de las prácticas consistentes en la solución de casos, es decir, lo que usualmente conocemos como "método del caso" ("MdC"). El "método del caso" o "de estudio de casos" es una técnica de aprendizaje que cuenta con cierta raigambre, incluso es definitorio de un determinado estilo de universidad. Pues se origina en torno a los años veinte en la Universidad de Harvard, precisamente con el fin de que los estudiantes de derecho se enfrentaran a situaciones reales y tuvieran que tomar decisiones, valorar actuaciones, emitir juicios fundamentados, etc. ${ }^{36}$.

Su justificación teórica podría complicarse ${ }^{37}$, pero en el fondo todos entendemos que -no en vano su denominación- esa metodología tiene por objeto la solución, por

36 Resulta realmente útil, y bastante sintético, Universidad Politécnica de Madrid, El Método del Caso. Guías rápidas sobre nuevas metodologías, Madrid, Servicio de Innovación Educativa de la Universidad Politécnica de Madrid, 2008. Tomo muy en cuenta esta Guía para mi breve exposición.

37 Sin que, necesariamente, se añada una mejor compresión de esta herramienta formativa. Veamos un ejemplo de lo que pretendo decir: "esta metodología se basa en planteamientos constructivistas donde la esencia del aprendizaje conlleva relacionar los conocimientos nuevos con los ya existentes generando estructuras progresivamente más ricas y complejas, por lo que la adquisición de conocimiento queda sustentada en los esquemas cognitivos que esa persona ya posee, es decir, en la 
parte de los estudiantes, de los casos prácticos que el profesor les presenta ${ }^{38}$. Aunque a renglón seguido hay que dejar claro que, teniendo en cuenta además que las soluciones jurídicas no tienen certeza matemática, lo que reviste verdadero interés no es la solución (si hubiera una única, posible), lo importante es el proceso seguido para estar en condiciones de ofrecer una solución plausible.

Es una técnica de aprendizaje activa y cooperativa (pues resulta conveniente que los estudiantes no trabajen de manera aislada), que ayuda al alumno a adquirir capacidad de análisis y de síntesis, la base para un estudio inductivo. Por lo que, indirectamente, permite paliar las consecuencias de los sistemas docentes demasiado basados en el método magistral.

Además, permite trabajar competencias transversales tanto de tipo instrumental (expresión oral y escrita, análisis y síntesis, organización y planificación, etc.) como de tipo interpersonal (reconocimiento de la diversidad, negociación, automotivación, liderazgo, etc.) [...] el método del caso permite también vincular la enseñanza con temas actuales y relevantes, superando la enseñanza basada en conceptos disciplinarios aislados y buscando una mayor interdisciplinariedad y transversalidad ${ }^{39}$.

El método del caso tiene tres presupuestos fundamentales ${ }^{40}$ : 1) los alumnos deben asumir un papel activo en el estudio del caso; 2) han de estar dispuestos a cooperar con sus compañeros, y 3) el diálogo es la base imprescindible para llegar a consensos y toma de decisiones conjuntas.

\section{El aprendizaje basado en problemas}

Se trata de una metodología con muchas similitudes con el "método del caso", pues ambas parten de un problema, pero se diferencian en la forma de ser llevadas a la

experiencia previa del estudiante [...]. En este sentido, el formador debe adaptar su forma de trabajar al nuevo enfoque de facilitador del aprendizaje y deberá impulsar el desarrollo de habilidades y actitudes tales como la autonomía, la capacidad de organización, la disciplina y la toma de decisiones en grupo". Aguado, I., Barrutia, J. M. a y Etxebarria, C., "Los estudios de casos como instrumento de innovación educativa en la enseñanza universitaria", cit., 113; Sánchez Hernández, C., "Método del caso y 'role-playing' en el ámbito del derecho civil”, en Mebiela Iglesia, P. et al. (eds.), Presente y futuro de la docencia universitaria, Ourense, Educación Editora, 2016, 477-482; FERNÁNDEZ SANCho, A. S. y LeiÑena MendizÁbal, E., "La aplicación del método de caso y del abP en el aprendizaje del derecho privado", en Elejalde García, M. J. y Pereira, J. A. (eds.), Los grados universitarios: posibilidades y caminos de innovación, Bilbao, Universidad del País Vasco, 2014, 133-154.

38 Partiendo de un problema real, se pide a los estudiantes una calificación jurídica de carácter profesional, con el fundamento teórico adecuado, con una propuesta de estrategias de solución y una evaluación de los resultados. Universidad Politécnica de Valencia, Método de casos, cit.

39 Aguado, I., Barrutia, J. M. a y Etxebarria, C., "Los estudios de casos como instrumento de innovación educativa en la enseñanza universitaria”, cit., 113.

40 Universidad Politécnica de Madrid, El Método del Caso, cit., 3. 
práctica y en los procesos de aprendizaje que siguen los estudiantes para la consecución de los objetivos previstos ${ }^{41}$.

El método del caso parte de la descripción de una situación real, respecto de la cual el alumno debe proporcionar alguna de las soluciones que sean posibles. En cambio, con la implementación del "aprendizaje basado en problemas" (“AbP”) "pretendemos que los alumnos sean capaces de 'construir conocimiento' de forma guiada por el profesor. En sentido estricto, y a diferencia del método del caso, el AbP no requiere que se incluya la solución de la situación o problema presentado. El objetivo es que el alumno sea capaz de descubrir qué necesita conocer para avanzar en la resolución de la cuestión propuesta" 42 . Los alumnos, en grupo, de forma autónoma y guiados por el profesor/a (tutor/a) deben encontrar la respuesta a una pregunta o solución a un problema. Pero, en sentido estricto, y a diferencia del método del caso, aquel no requiere que se incluya la solución del problema presentado: lo importante aquí es identificar los problemas que suscita el supuesto de hecho, y relacionarnos con los conocimientos teóricos adquiridos en la asignatura ${ }^{43}$. Es decir, la diferencia significativa entre ambas metodologías es que el AbP desarrolla las habilidades y destrezas del estudiante para "problematizar": tiene que partir de un supuesto y saber encontrar, desde el punto del derecho, los problemas que pueden recibir una calificación jurídica. Pero sin necesidad de continuar el proceso hasta la solución que sería propia del MdC.

En realidad, personalmente opino que no resulta especialmente relevante lograr la distinción entre el MdC y el AbB, más allá de su distinta denominación. Ambas son propuestas que utilizan enfoques interesantes de una misma actividad docente, y lo más importante es que ambas pueden combinarse en una secuencia de trabajo que, comenzando por la calificación jurídica, concluye con una solución. En el fondo, creo que la distinción resulta poco útil desde el momento en que ni una ni otra metodología se implementan siempre con el mismo modo de hacer, caben variaciones y combinaciones. Sobre todo, dado que sostengo la necesidad de que cada profesor (convenientemente ilustrado por los avances que nos facilitan los expertos en esta materia) encuentre un método personal que se adapte a las circunstancias (las propias y las del contexto docente).

41 Ibíd., 7, donde puede verse el interesante cuadro comparativo tomado de otros autores.

42 Font RiBas, A. et al., "Las dificultades del aprendizaje autónomo en un contexto de ABP", Revista de Educación y Derecho, n. ${ }^{\circ}$ 1, 2009, 1-26; Fernández Sancho, A. S. y Leiñena Mendizábal, E., "La aplicación del método de caso y del ABP en el aprendizaje del Derecho Privado", cit., 134; RECIO RAMíREZ, M. á Á., "El aprendizaje basado en la resolución de problemas: una experiencia práctica”, cit.; Bonet SÁnchez, M. a P., “Aprendizaje basado en problemas”, en Mestre, I. y Mestre, R. M., Guía práctica para la enseñanza del derecho a través de las clínicas jurídicas: diez años de experiencia de la Clínica Jurídica per la Justicia Social de la Facultat de Dret de la Universitat de Valéncia, Valencia, Tirant lo Blanch, 2018, 93-98.

43 Fernández Sancho A. S. y Leiñena Mendizábal, E., "La aplicación del método de caso y del abp en el aprendizaje del derecho privado", cit., 140. 


\section{Las tecnologías de información y comunicación}

Las tecnologías de información y comunicación (TICS) constituyen una herramienta fundamental de la docencia moderna, en virtud de adelantos técnicos -fácilmente accesibles- cuyo uso resulta insoslayable no solamente en la docencia sino, por las exigencias del ritmo de vida actual, en cualquier sector de actividad humana (y no humana $\left.{ }^{44}\right)$. Es un hecho constatable, basta, para comprobarlo, que fijemos la vista en tantos objetos con los que contamos en el entorno del aula docente ${ }^{45}$. No solamente es así en la propia realidad de las cosas, sino que este presente ya se aventuró con el diseño de las reformas de "Bolonia": en el proceso de enseñanza-aprendizaje de las universidades europeas, las Tics serían medulares. Imprescindibles a la hora de alcanzar los retos planteados en el proyecto de convergencia en el EEES, en cuanto a la innovación en las formas de generación y transmisión del conocimiento y a la apuesta por una formación continuada a lo largo de toda la vida ${ }^{46}$.

Pero no podemos equivocarnos pensando que las Tics son meros adelantos (tan esenciales que su desaparición pondría en riesgo la supervivencia de las sociedades desarrolladas) de comunicación y ofimática (valiéndonos de dispositivos cada vez más novedosos, cada vez más rápidos y más potentes, gracias a tantos adelantos tecnológicos sobre el ciberespacio, en microcomputación y programación, o si se quiere, hardware y software). Constituyen, en nuestro ámbito, un recurso didáctico, un instrumento para la organización, gestión y administración educativa, y/o como instrumento para la investigación. Las TICs son:

... un conjunto de procesos y productos derivados de las nuevas herramientas (hardware y software), soportes de la información y canales de comunicación, relacionada con el almacenamiento, procesamiento y transmisión digitalizados de la información de forma rápida y en grandes cantidades. [...] [L]os rasgos distintivos de estas tecnologías hacen referencia a la inmaterialidad, interactividad, instantaneidad, innovación, elevados parámetros de calidad de imagen y sonido, digitalización, influencia más sobre los procesos que sobre los productos, automatización, interconexión y diversidad $^{47}$.

44 Hoy en día se utiliza la denominación "M2M", para hacer referencia a la "comunicación máquinamáquina'.

45 No vale la pena plantear comparaciones con otro tiempo respecto de la megafonía de las aulas, la accesibilidad actual de los medios reprográficos, la existencia de páginas web, correo electrónico, bases de datos, revistas electrónicas, la enseñanza en línea, encuestas y evaluaciones también on line, videoconferencias, chat, y tantas cosas más. Por extraño que parezca, hay que confesar que no siempre han existido.

46 Ferrer Soto, C., Martínez Senra, A. I. y Otero Neira, M. ${ }^{a}$ C., "Ventajas del uso de las tics en el proceso de enseñanza-aprendizaje desde la óptica de los docentes universitarios españoles", EDUTEC. Revista Electrónica de Tecnología Educativa, n. ${ }^{\circ}$ 29, 2009.

47 Ferrer Soto, C., Martínez Senra, A. I. y Otero Neira, M. a C., "Ventajas del uso de las tics en el proceso de enseñanza-aprendizaje desde la óptica de los docentes universitarios españoles”, cit., 2-3. 
Las ventajas que proporciona el progreso técnico y científico son evidentes ${ }^{48}$. Sin embargo, puede resultar más difícil enunciarlas de manera exacta y objetiva en el contexto de la relación docente. Quiero decir que el mayor o menor entusiasmo por lo que han aportado puede relativizarse según gustos y experiencias de cada profesor.

Para concluir, aunque no voy a abordarlos específicamente por resultar sobradamente conocidos, existen diversos recursos ofimáticos (algunos gratuitos) que pueden ser utilizados para presentaciones, como repositorios de información (almacenamiento "en la nube"), formularios, hojas de cálculo, diapositivas y videos, o para trabajo colectivo y "en línea" de los estudiantes, para crear blogs, etc.

Hay ciertas aplicaciones que, en este momento al menos, resultan de empleo habitual. Tal es el caso de Google Drive, OneDrive, Poetica, Drop Box, Power Point, Keynote, Google Slides, Prezi, Camtasia Studio, PowToon, EduCanon, SlideShare, Youtube, Vimeo, WordPress, Wix o Blogger.

\section{Las flip teaching, flipped learning, flipped classroom}

Se trata de expresiones que traducimos como "clase invertida" o "aula invertida". Es esta una de las herramientas que mejor ejemplifica el nuevo paradigma del proceso educativo centrado en el estudiante ${ }^{49}$. Tiene carácter semipresencial o mixto, y se utiliza normalmente haciendo uso de las nuevas tecnologías de comunicación. Admite muy diversas variantes (en tanta medida como se ha difundido), pero la idea básica consiste en que se invierte el proceso de creación-transmisión de información: con la clase invertida, no va desde el profesor a los estudiantes, sino que son estos los que elaboran una información (como puede ser una lección) que luego someten al profesor y debaten en el aula tradicional ${ }^{50}$. Son los alumnos los que se adelantan a

48 Y también algunos inconvenientes. Es posible que la realización de cometidos nuevos solamente pueda conseguirse sacrificando más tiempo (el necesario para gestionar todos esos adelantos). Además de otro tipo de efectos indeseados: aumento de informaciones no fiables, dificultades para localizar-seleccionar-analizar la información, los riesgos de ansiedad o comportamientos adictivos, problemas posturales, de cuidado de la vista, de falta de sociabilidad no virtual, etc. Ibíd., 9.

49 Chaparro Matamoros, P., "La enseñanza online en los estudios universitarios the e-learning in higher education", Actualidad Jurídica Iberoamericana, n. . 4.bis (extraordinario), 2016, 9-26; OlaizoLA, A., "La clase invertida: usar las тіс para dar la vuelta a la clase", [en línea], disponible en: http:// www.academia.edu/8350587/LaclaseinvertidausarlasTICparadarvueltalaclase [consultado el 30 de enero de 2020]; Esteve Segarra, M. a A., "“Flipped teaching' o la clase invertida en la enseñanza del derecho", Actualidad Jurídica Iberoamericana, n. ${ }^{\circ}$ 4.bis (extraordinario), 2016, 75-95; ZARAGOZA Martí, M. ${ }^{a}$ F. y Zaragoza Martí, A., "La docencia invertida y la simulación de juicios como una nueva metodología del aprendizaje jurídico", en RoIG-VILA, R., Investigación en docencia universitaria: diseñando el futuro a partir de la innovación educativa, Barcelona, Octaedro, 2017, 754-764.

50 'El 'Flipped Classroom' o 'Flipped teaching' es un modelo de aprendizaje basado en el uso de determinados materiales como vídeos y lecturas fuera del aula, utilizando el tiempo de clase para la adquisición y práctica de conocimientos. [...] La técnica de 'flipear' una clase puede partir de la edición de un vídeo sobre el contenido que se quiere exponer, o bien de la utilización de materiales disponibles en la red, o bien de la elaboración y publicación en línea de apuntes, podcasts u 
preparar la clase, fuera del aula, lo que les compromete en el proceso de formación y les hace más participativos. El profesor suministra previamente los materiales necesarios para el trabajo del estudiante, supervisa el proceso, hace las correcciones que fueran oportunas, e insiste en la asimilación de contenidos por parte de los alumnos cuando se reúnen en el aula.

\section{Otras metodologías}

Por amplia que fuese la relación de posibilidades de que disponga el profesor, siempre podría ampliarse con alguna metodología nueva. Pero una cosa es que exista una variedad de recursos potenciales y otra que realmente valga la pena el riesgo de aventurarse a ensayarlos con los estudiantes. A diferencia de otras titulaciones (como sucede en las de magisterio) en que la propia experimentación pedagógica forma parte de los contenidos curriculares, en el caso del derecho no resulta imprescindible hacerlo en función del tiempo disponible. Me resulta tranquilizadora alguna opinión (que voy a seguir en los párrafos siguientes) ${ }^{51}$ que abiertamente distingue entre "metodologías educativas conocidas y aplicadas", aquellas otras que "se conocen pero no se aplican" y, finalmente, las que resultan en general "desconocidas" 52 .

En cuanto a las metodologías docentes que se conocen pero no se emplean por los profesores, la razón puede ser simple: "el esfuerzo que requieren es muy alto. Suelen estar relacionadas con los paradigmas basados en el aprendizaje" ${ }^{53}$. Como sucede con la evaluación diagnóstica (sobre lo que sabe y lo que ignora el estudiante); la evaluación por evidencias o "rastros" que se van dejando por el estudiante

otros materiales. Las ventajas de este método son varias. En primer lugar, determinados procesos de aprendizaje se desarrollan fuera del aula, los alumnos no pierden tiempo de clase escuchando las explicaciones y el tiempo presencial se puede utilizar para reforzar aspectos que requieren un contacto más directo e individualizado del docente con los estudiantes. A su vez, ello fomenta una participación más activa del estudiante al tener que asimilar los conocimientos fuera del aula para practicarlos dentro. En segundo lugar, permite a los estudiantes elaborar su aprendizaje mediante un método constructivo y adaptado a la diversidad. En tercer lugar, el método permite a los estudiantes reaprender contenidos visionando, cuantas veces necesite, los contenidos elaborados". EsTEVE Segarra, M. ${ }^{a}$ A., "“Flipped teaching' o la clase invertida en la enseñanza del Derecho", cit., 81-82.

51 Fidalgo, Á., "Metodologías educativas-innovación educativa”, cit.

52 Ejemplos de metodologías poco o nada conocidas pueden ser los siguientes. Tutoría proactiva: "se basa en anticiparse a la demanda de información por parte del alumno; es una metodología altamente eficaz, ya que el objetivo es resolver la duda en el momento en que se produce (realmente antes de que se produzca)". Trabajo cooperativo: no es un mero trabajo en grupo, se trata de aprovechar los recursos creados por los propios alumnos y los profesores. "Ciclo de Kolb": "se basa en la acción como efecto transformador del conocimiento; entre acción y acción se relaciona el resultado con los conocimientos abstractos. Es una metodología muy eficaz para asignaturas en las que se quiera enfocar hacia la adquisición de habilidades y capacidades". Inteligencia colectiva: "El planteamiento es gestionar el conocimiento que produce el grupo (por ejemplo en una clase) de tal forma que se sumen conocimientos. El resultado de los conocimientos del grupo se denomina inteligencia colectiva y se puede aplicar para mejorar el aprendizaje individual”. Ibíd.

53 Ibíd. 
cuando emplea determinadas TICs; la evaluación formativa (se comprueba el aprendizaje para tomar, en su caso, acciones correctoras específicas); la formación personalizada (se trata de adaptar los recursos y estrategias formativas a las condiciones personales de cada alumno); los trabajos individuales y grupales tipo "caja blanca" (en los que el profesor participa como miembro del equipo de trabajo).

Me parece llena de sentido común, aunque a veces podamos distraernos con el atractivo de lo más novedoso, la siguiente conclusión: "Muchas personas piensan que la innovación educativa se basa, precisamente, en introducir estas metodologías en la formación; sin embargo, el objetivo de la innovación educativa en este tipo de metodología es reducir el esfuerzo para implantarlas, dicho de otra forma, poder utilizarlas sin aumentar el esfuerzo actual" 54 .

Como ya he explicado, las metodologías docentes en el ámbito del derecho resultan necesariamente abiertas y provisionales. Creo que podría afirmar que cada día existe un término o una actividad que puede ser "descubierto". En correspondencia, resultaría ilusorio pretender por mi parte una exposición concreta de todas las posibilidades materiales de que potencialmente puede valerse un profesor en el aula, y fuera de ella, para lograr una adecuada formación de sus estudiantes. Además, se trata de herramientas que puede suceder que se adapten al derecho que enseñamos de una manera bastante relativa (lo que las convierte en secundarias, respecto de otras metodologías principales), o en ocasiones resultan demasiado complicadas y su puesta en práctica precisa de un proceso previo de formación específica para los estudiantes, o bien simplemente no son rentables en términos de resultados, tiempo y esfuerzo invertidos. Con todo, mencionaré las más interesantes, aunque sea de manera breve.

\section{Probática}

El "arte" de probar en juicio es algo distinguible del derecho probatorio, por mucho que guarden una estrecha relación ambos aspectos, y que responde a unas determinadas técnicas que precisamente desarrolla la probática ${ }^{55}$.

La probática es una epistemología de la prueba concebible como ciencia aplicada para lograr, partiendo de una previa actividad investigadora, la reconstrucción de los hechos en el proceso judicial al objeto de poder sentar su evidencia. Su relación con el derecho procesal, y más concretamente con el derecho probatorio, es puramente instrumental ya que este último sólo le facilita y a veces coarta los medios para que aquella pueda rendir su finalidad. En las facultades de derecho de corte romanístico, no ya la probática, sino ni tan siquiera el derecho probatorio constituyen disciplinas

54 Ibíd.

55 Muñoz Sabaté, L. 1., Introducción a la probática, Barcelona, Bosch, 2008 y MuÑoz Sabaté, L. I., "Reflexiones sobre la probática o ciencia de la prueba judicial", La Ley, n. . 7128, 2009. 
desgajadas del derecho procesal, y sólo aparecen y prosperan como meras habilidades que se enseñan sin método ni concierto en las pasantías o en algunas escuelas de práctica jurídica ${ }^{56}$.

\section{Jurimetría}

Más que de una metodología docente, se trata de una herramienta informática (que tiene especial virtualidad en las actividades prácticas, y singularmente en la metodología del caso). Concretamente, es una herramienta de analítica jurisprudencial ${ }^{57}$ que obtiene resultados estadísticos a partir de procesos de big data, que tabulan un volumen ingente de decisiones judiciales. Podría decirse, aun con inexactitud, que la jurimetría es la programación informática que ofrece un resultado medible sobre la predictibilidad de las decisiones de un tribunal en un asunto concreto.

Con todo, tal vez porque se trata de algo realmente novedoso, todavía suscita algunas desconfianzas ${ }^{58}$.

\section{Gamificación en el aula}

Se trata de la españolización del término anglosajón game, utilizado en el sentido de “aprender jugando". Significa el uso de la "mecánica de los juegos" en otras actividades al margen de lo puramente recreativo, como en la enseñanza ${ }^{59}$. Y encuentra su motivación en el gran arraigo de que disfrutan entre los jóvenes las actividades lúdicas a través de dispositivos móviles y redes sociales; forma parte del concepto de metodologías integradas dentro del enfoque pedagógico de Flipped Classroom.

Cuando se aplica al derecho, la gamificación tiene por objeto actividades de juego o de superación de "retos", con un preponderante componente jurídico, y siguiendo una serie de reglas básicas (a modo de "reglas del juego") como si se tratase de un producto de entretenimiento: caracterización con avatares (es decir, la representación que quiere otorgarse a sí mismo un usuario para su identificación), puntuación obtenida, clasificación competitiva (de los estudiantes entre sí, que determina el respectivo status), superación de niveles, recompensas, etc. Se trata de una metodología activa para el estudiante, una vez que ha sido diseñada por el profesor,

56 MuÑoz Sabaté, L. I., Introducción a la probática, cit., resumen de la contraportada de la monografía.

57 Disponible en: http://jurimetria.wolterskluwer.es/content/Inicio.aspx [consultado el 20 de enero de 2020].

58 Es bien significativo Biurrun, F. J., "Se puede predecir el resultado de una sentencia", Actualidad Jurídica Aranzadi, n. ${ }^{\circ}$ 929, 2017, 28: "Se puede predecir el resultado de una sentencia". De la estadística a la predictibilidad hay un abismo, viene a concluirse. En términos más optimistas, Molina GARcía, M. a J., "Jurimetría: tecnología punta y su aplicación práctica en el sector legal”, Actualidad Civil, n. ${ }^{\circ} 7-8,2017,80-83$

59 DíAz, C., "Reingeniería jurídica aplicada a la gamificación”, Management Review, vol. 2, n. 3, 2007. 
con reglas o variables tan particulares como quieran establecerse, y de complejidad abierta $^{60}$. La utilidad de los recursos que, en sentido amplio, consideramos como game-based learning se apoya en la motivación que los juegos en general suponen para determinados destinatarios. El estímulo resulta todavía más incentivado (en el contexto cultural de la generalidad de los alumnos) cuando se realiza a través de aplicaciones radicadas en dispositivos electrónicos interconectados.

Expresiones $^{61}$ como Kahoot o Quizizz (ambas para confeccionar cuestionarios on line), o Socrative (test de preguntas), se relacionan precisamente con aplicaciones informáticas $(A P P)$ con una mecánica operativa diseñada para incorporar juegos y con una finalidad docente. Obviamente en este contexto, aunque se pueda "jugar" en el aula, la relación entre cada alumno, el conjunto de jugadores, y el profesor tiene lugar en un escenario "virtual", a través de una plataforma de internet.

\section{PechaKucha}

La idea matriz de esta denominación (PechaKucha) tiene que ver, en idioma japonés, con una "charla" o "reunión breve". Es un recurso general (que se traslada también a la pedagogía), utilizado en eventos culturales o sociales de todo tipo, para transmitir de manera muy breve una idea mediante presentaciones audiovisuales (diapositivas) que tienen una característica fundamental: su brevedad, pues de lo que se trata es de captar la atención del público, sin distracciones que supongan una pérdida de información. En tal sentido está muy difundida la modalidad "20x20": consistente en llevar a cabo una presentación temática mediante veinte diapositivas, cada una de las cuales se expone durante veinte segundos ${ }^{62}$. Pueden celebrarse sesiones, o reuniones, en que se lleve a cabo más de una presentación, siempre y cuando no se sature a los destinatarios, sin que la comunicación deje de resultar amena.

\section{Wikis como instrumento docente}

Las Wikis son plataformas para el trabajo colectivo de los estudiantes. A partir de un determinado software, se utilizan como una especie de procesador de texto en que todos los estudiantes del grupo pueden participar desde dispositivos electrónicos diferentes.

60 Tanto como quiera la imaginación del creador del juego: puede ir desde un simple crucigrama o una "sopa de letras" jurídicos, cuestionarios o formularios, hasta los juegos avanzados de rol interactivos.

61 Artal Sevil, J. S., "Kahoot, Socrative \& Quizizz: herramientas gratuitas para fomentar un aprendizaje interactivo y la gamificación en el aula”, en AlejandRe MarCo, J. L. (coord.), Buenas prácticas en la docencia universitaria con apoyo de TIC. Experiencias en 2016, Zaragoza, Universidad de Zaragoza, 2017, 17-27.

62 Domínguez Albero, S., Martínez Calvo, J. y Martínez Navarro, M., "Implementación del método PechaKucha (presentaciones 20x20) en el ámbito del grado en derecho", en AlEJANDRE MARCo, J. L. (coord.), Buenas prácticas en la docencia universitaria con apoyo de TIC, cit., 135-144. 


\section{Project-based learning}

El "aprendizaje orientado a proyectos" (AoP) es un método de trabajo que se caracteriza porque se propone a los estudiantes un determinado resultado (p. ej., una concreta reclamación), y son ellos los que deben establecer las estrategias necesarias para alcanzarlos. Es importante la secuencia genérica que debe seguirse: comenzando por el planteamiento de necesidad del resultado pretendido, los estudiantes proceden al acopio de información, y a partir de su análisis proponen alguna de las alternativas posibles.

\section{Lesson plans, con Symbaloo}

Se trata de un itinerario de aprendizaje diseñado por el profesor y que los alumnos van recorriendo mediante "botones" de una presentación que contiene determinados enlaces. Además de la información que se transmite, se pueden añadir al diseño características adicionales como el cómputo del tiempo que el alumno invierte en el recorrido. La aplicación Symbaloo se ha diseñado para el uso de esta metodología, de tal modo que es frecuente asociar uno y otro término.

\section{E. Seminarios y talleres}

Uno de los problemas con que puede tropezar el profesor en el desarrollo docente es el de determinar el nivel general o término medio entre el interés de los alumnos por la materia que explica y los contenidos extensos de esta. En la duda, soy partidario del criterio de "economía docente", es decir, de no saturar de información a los estudiantes. ¿Qué debe enseñar el profesor a todos los alumnos inexcusablemente? Y, de otro lado, ¿qué aspectos del derecho pueden tener un carácter (ya subordinado, o ya muy especializado) que permite que sean ofrecidos solamente a algunos alumnos? Es precisamente en cuanto a esto último que se demuestra la utilidad de ciertos medios docentes que quedan reservados solamente a aquellos alumnos que, de modo particular, tienen interés en materias o contenidos específicos y cuyo aprovechamiento queda a su iniciativa. Me refiero, singularmente, a los "seminarios", expresión genérica que podría ser sinónima de "cursos especiales" (en contraposición a los "generales", o que forman parte de la docencia reglada de una titulación).

Los seminarios son netamente diferenciables tanto de las clases teóricas (en que prepondera la intervención del profesor) como de las prácticas (en que se exige una mayor participación del alumno), pues en aquellos profesor y discípulo trabajan en un esfuerzo común ${ }^{63}$. Pueden tener muy diverso objeto (conducir la investiga-

63 Pujol Balcells, J. y Fons Martín, J. L., Los métodos en la enseñanza universitaria, Pamplona, EUNSA, 1978, 96. 
ción del grupo en ciertos temas concretos ${ }^{64}$, desarrollar actividades de discusión o debate dirigido por el profesor, utilizar metodologías específicas, o formar sobre su mecánica, etc.), pero en todo caso suponen un medio docente especializado en ciertos temas, para el que conviene exigir de los participantes un determinado nivel de conocimientos a fin de que resulten más provechosos; al tiempo, por ser reducido el número de los estudiantes inscritos (necesariamente, para permitir una interrelación), resulta más fácil el trabajo coordinado profesor-alumnos ${ }^{65}$.

Los talleres comparten la finalidad de los seminarios de profundizar en un conocimiento especializado, a partir de un pequeño grupo de estudiantes. Sin embargo, el taller pone el énfasis en cuestiones de carácter práctico, que pretenden conectarse con los conocimientos teóricos que previamente poseen los participantes.

\section{F. Tutorías}

Las tutorías docentes propiamente dichas (del profesor encargado de una determinada asignatura, con los estudiantes matriculados en ella) son la mejor ocasión para que cada alumno reciba una atención personal o personalizada por parte del profesor. Aunque constituyen un derecho del alumno (de todos ellos, por supuesto) y, correlativamente, es obligación del profesor ofrecer esta asistencia docente, todos sabemos que en la práctica solamente es avalado por una mayoría de los alumnos ante la inminencia de la fecha de un examen (y no solamente para preguntar cuestiones conceptuales o de contenido del temario, pues en ocasiones se refieren a aspectos de carácter administrativo). Por eso la realidad consigue adaptar la disponibilidad material de tiempo frente al número teórico de alumnos (los matriculados en cada curso) que, en su derecho, podrían acudir a la tutoría.

Son muchas las ventajas que puede ofrecer el sistema de tutorías, cuando se quiere aprovecharlas. Evidentemente, para empezar, permite resolver las dudas que al alumno le haya suscitado un tema expuesto en la clase teórica; aunque personalmente soy partidario de que, siempre que sea posible, ese tipo de preguntas se formulen durante o al término de la clase teórica, puesto que tales cuestiones pueden no ser exclusivas de un solo alumno y en todo caso su solución normalmente contribuye a enriquecer lo explicado previamente. También permiten las tutorías resolver las cuestiones que tienen un carácter más administrativo o burocrático, que afecten a un alumno en particular, o bien orientarle en cuanto a los métodos de estudio con que enfrentarse a la asignatura, o simplemente propician (tampoco es poca cosa) la

64 Esa además fue la finalidad principal que originariamente se atribuyó a los seminarios. GARCía Garrido, M. y Eugenio y Díaz, F., Estudios de derecho y formación de juristas, Madrid, Dykinson, 1990., 183.

65 Se trata, en suma, de un instrumento docente que ofrece una importante utilidad, no faltando incluso quienes lo consideran la mejor técnica de aprendizaje de la enseñanza superior; así CAPELLA, J. R., El aprendizaje del aprendizaje, cit., 64. 
humanización de la relación docente ( frecuencia se despersonaliza o diluye en el anonimato del grupo ${ }^{66}$.

Hoy en día los recursos técnicos y su universalización en los medios docentes ofrecen con creciente facilidad posibilidades de tutoría, distintas del encuentro personal, aprovechando los sistemas de comunicación telemáticos (tanto de internet como de telefonía): en ocasiones se las denomina "tutorías virtuales" o "no presenciales". Así, los adelantos tecnológicos permiten sendas modalidades genéricas de tutoría: la que se denomina "tutoría electrónica asíncrona" (con un lapso temporal en la comunicación (como sucede con el correo electrónico, los foros o los chats) y la "tutoría electrónica sincrónica", en la que hay una simultaneidad en la comunicación (como en la videoconferencia y en la "pizarra electrónica"). A su vez, admiten diversas modalidades genéricas, según el número de alumnos y profesores que relacionen (puede tratarse de una tutoría "directa", "compartida" o "colectiva").

Pero creo que el tipo de contacto que establece la tutoría tradicional no puede ser enteramente sustituido por las ventajas que aportan otras innovaciones. Proporcionan, eso sí, un valor añadido, pero con ellas se pierde buena parte de la utilidad consistente en esa especie de personalización de la relación docente a la que ya me he referido. Y pueden suponer una sobrecarga de trabajo para el profesor (incluso una forma de "control" por parte de sus alumnos), que debe poner cuidado en establecer claramente cuáles son las reglas y límites de su utilización.

\section{Conclusiones}

Mis conclusiones han de ser forzosamente breves. Fundamentalmente porque la naturaleza de este trabajo es meramente expositiva de un repertorio de posibilidades docentes, destinadas a los especialistas o profesores (es decir, quienes profesan o manifiestan que están en posesión de un determinado conocimiento o ciencia) del derecho. No pretendo persuadir a mis colegas sobre la conveniencia absoluta de ninguna técnica de enseñar. En mi tierra solemos utilizar un viejo dicho, que resume mi intención mejor de lo que yo puedo hacerlo: "cada maestrico tiene su librico...".

A pesar de los condicionantes del contexto (que ha cambiado de una manera evidente con la creación del EEES), en el fondo son las peculiares aptitudes del enseñante (incluso su talante personal) las que acaban ultimando la pregunta básica que él mismo puede formularse: ¿cómo aprenden mis propios alumnos? No cabe duda de que en la pedagogía universitaria instaurada tras la Convergencia europea se ha producido una importante alteración de algunos paradigmas tradicionales sobre la formación de los estudiantes ¿Qué es lo que el profesor puede exigir realmente a sus

66 Creo que es experiencia compartida que basta con que el alumno se sienta escuchado de manera personal para que cambie su actitud ante la asignatura, y para que su rendimiento académico mejore. No es fácil describir la satisfacción como profesor cuando alguno de los alumnos que han atravesado circunstancias difíciles que han estado a punto de apartarles de la carrera académica la concluyen y obtienen plazas de empleo público o desempeñan exitosamente otros trabajos. 
alumnos? ¿El denostado virtuosismo de la memoria? Ya no, al menos en la teoría del sistema "Bolonia". Es ahí donde la nueva instrucción docente intenta justificar su utilidad: el estudiante no necesita retener (al menos en la medida en que antes se exigía poseer un cierto volumen de conocimientos, materialmente almacenados en la memoria) lo que con facilidad puede obtener a través de los recursos modernos de información y documentación (de nuevo, la importancia de las TICs). El cometido del profesor es facilitar a sus alumnos la adquisición de competencias, generales y específicas, y el desarrollo de destrezas. El cómo lograrlo forma parte de una decisión personal, que puede ilustrarse con descubrimientos de la psicopedagogía, incluso con algunas tendencias. Y hasta con aportaciones tan modestas como este mismo trabajo, que confío a la benevolencia de mis colegas.

\section{Referencias}

Aguado, I., Barrutia, J. M. a y Etxebarria, C., "Los estudios de casos como instrumento de innovación educativa en la enseñanza universitaria", en ELEJALDE García, M. a J. y Pereira J. A. (eds.), Los grados universitarios: posibilidades y caminos de innovación, Bilbao, Universidad del País Vasco, 2014, 109-132.

Artal Sevil, J. S., "Kahoot, Socrative \& Quizizz: herramientas gratuitas para fomentar un aprendizaje interactivo y la gamificación en el aula", en AlEJANDRE MARCO, J. L. (coord.), Buenas prácticas en la docencia universitaria con apoyo de TIC. Experiencias en 2016, Zaragoza, Universidad de Zaragoza, 2017, 17-27.

B AIN, K., Lo que hacen los mejores profesores de universidad, Valencia, Universidad de Valencia, 2007.

BALdus, Ch., "Calidad: ¿para qué, para quién? Una perspectiva alemana y continental sobre el llamado proceso de Bolonia", El Cronista del Estado Social y Democrático de Derecho, n. ${ }^{\circ}$ 4, 2009, 14-19.

Bernad, J. A., Estrategias de enseñanza-aprendizaje en la universidad, Zaragoza, Universidad de Zaragoza, 1991.

Biurrun, F. J., "Se puede predecir el resultado de una sentencia", Actualidad Jurídica Aranzadi, n. ${ }^{\circ}$ 929, 2017, 28.

Bonet SÁnchez, M. ${ }^{a}$ P., “Aprendizaje basado en problemas”, en Mestre, I. y Mestre, R. M., Guía práctica para la enseñanza del derecho a través de las clínicas jurídicas: diez años de experiencia de la Clínica Jurídica per la Justicia Social de la Facultat de Dret de la Universitat de Valéncia, Valencia, Tirant lo Blanch, 2018, 93-98. 
Cano García, M. ${ }^{a}$ E., "La evaluación por competencias en la educación superior", Profesorado. Revista de Currículum y Formación de Profesorado, vol. 12, n. ${ }^{\circ}$ 3, 2008, 1-16.

Capella Hernández, J. R., El aprendizaje del aprendizaje, 2. ed., Madrid, Trotta, 1998.

Cavanillas Múgica, S., "La enseñanza del derecho según la 'Institución Libre de Enseñanza"”, Revista de Educación y Derecho, n. ${ }^{\circ} 11$ (dedicado a: Modelos de clínicas jurídicas en España), 2015, 1-20.

Chaparro Matamoros, P., "La enseñanza online en los estudios universitarios "the e-learning in higher education"”, Actualidad Jurídica Iberoamericana, n. . 4.bis (extraordinario), 2016, 9-26.

De La Cruz, M. á. Á, "Necesidad y objetivos de la formación pedagógica del profesor universitario", Revista de Educación, n. 331 (dedicado a: La formación del profesorado universitario), 2003, 35-66.

De LA CRUZ, M. á Á., La concepción del profesor como mediador entre la disciplina y los estudiantes, Zaragoza, Instituto de Ciencias de la Educación Universidad de Zaragoza, Colección Documentos, n. ${ }^{\circ}$ 2, 2005.

De La Peña Amorós, M. ${ }^{a}$ M., "La evaluación de las prácticas en el grado en derecho", Revista de Educación y Derecho, n. ${ }^{\circ}$ 10, 2014, 1-22.

DíAz, C., "Reingeniería jurídica aplicada a la gamificación", Management Review, vol. 2, n. $3,2007$.

Diéguez Oliva, R., "Implantación experimental de alguna de las técnicas de los acuerdos de la Declaración de Bolonia en la titulación de derecho, en especial, derecho civil III: derechos reales y registro de la propiedad", en RoDRíGUEZ ORTEGa, N. (coord.), Acción tutorial, reflexión y práctica: una experiencia de interacción docente en la Universidad de Málaga, Málaga, UMA, 2008, 153-158.

Domínguez Albero, S., Martínez Calvo, J. y Martínez Navarro, M., "Implementación del método PechaKucha (presentaciones 20x20) en el ámbito del grado en derecho", en Alejandre MARCo, J. L. (coord.), Buenas prácticas en la docencia universitaria con apoyo de TIC. Experiencias en 2016, Zaragoza, Universidad de Zaragoza, 2017, 135-144. 
Esteban BARA, F., "Vuelta al pasado de la universidad para repensar su futuro", en LAUdo, X. y Vilafranca, I. (coords.), ¿Enseñar y aprender en la universidad? Ensayos fenomenológicos y hermenéuticos, Barcelona, Universidad de Barcelona, 2016, 137-162.

Esteve Segarra, M. ${ }^{a}$ A., “'Flipped teaching' o la clase invertida en la enseñanza del derecho", Actualidad Jurídica Iberoamericana, n. " 4.bis (extraordinario), 2016, 75-95.

Fernández Sancho, A. S. y Leiñena Mendizábal, E., "La aplicación del método de caso y del ABP en el aprendizaje del derecho privado", en ElEjalde GARCíA, M. ${ }^{\text {a }}$ J. y PEREIRA, J. A. (eds.), Los grados universitarios: posibilidades y caminos de innovación, Bilbao, Universidad del País Vasco, 2014, 133-154.

FIDAlgo, Á., "Metodologías educativas-innovación educativa. Conceptos, recursos y reflexión sobre innovación educativa", [en línea], disponible en: https://innovacioneducativa.wordpress.com/2007/10/08/metodologias-educativas [consultado el 12 de enero de 2020].

Ferrer Soto, C., Martínez Senra, A. I. y Otero Neira, M. C C., "Ventajas del uso de las TICs en el proceso de enseñanza-aprendizaje desde la óptica de los docentes universitarios españoles", EDUTEC. Revista Electrónica de Tecnología Educativa, n. ${ }^{\circ} 29,2009$.

Font Ribas, A. et al., "Las dificultades del aprendizaje autónomo en un contexto de ABP”, Revista de Educación y Derecho, n. . 1, 2009, 1-26.

García Garrido, M. E. y Díaz, F., Estudios de derecho y formación de juristas, Madrid, Dykinson, 1990.

GonZÁLEz Rus, J. J., "Reflexiones sobre el futuro de la enseñanza del derecho y sobre la enseñanza del derecho en el futuro", Revista Electrónica de Ciencia Penal y Criminología, n. ${ }^{\circ}$ 5, 2003, 1-21.

LóPEZ-Sidro, Á., "Reflexiones sobre los desafíos de Bolonia y la misión del profesor universitario. Entre la innovación y la tradición”, Revista Jurídica de Investigación e Innovación Educativa, n. ${ }^{\circ}$ 4, 2011, 23-44.

Martínez Martín, M., "La universidad en la sociedad contemporánea", en Laudo, X. y Vilafranca, I. (coords.), ¿Enseñar y aprender en la universidad? Ensayos fenomenológicos y hermenéuticos, Barcelona, Universidad de Barcelona, 2016, 9-12. 
Marrades Puig, A. I., "Innovación educativa en las clases de derecho constitucional I a través de las actividades aplicadas y complementarias", Revista General de Derecho Constitucional, n. ${ }^{\circ} 21,2015$.

Molina García, M. a J., "Jurimetría: tecnología punta y su aplicación práctica en el sector legal”, Actualidad Civil, n. ${ }^{\circ}$ 7-8, 2017, 80-83.

NúÑEz, C. E., Universidad y ciencia en España. Claves de un fracaso y vías de solución, Madrid, Gadir, 2013.

Muñoz SABATÉ, L. 1., Introducción a la probática, Barcelona, Bosch, 2008.

MuÑoz Sabaté, L. 1., "Reflexiones sobre la probática o ciencia de la prueba judicial”, La Ley, n. ${ }^{\circ}$ 7128, 2009.

Muñoz Sabaté, L. 1., Summa de probática civil, 3. a ed., Madrid, La Ley, 2018.

Olaizola, A., "La clase invertida: usar las TIC para dar la vuelta a la clase", [en línea], disponible en: http://www.academia.edu/8350587/LaclaseinvertidausarlasTICparadarvueltalaclase [consultado el 30 de enero de 2020].

Petschen, S., El arte de dar clases. Experiencias de los autores de libros de memorias, Madrid, Plaza y Valdés, 2013.

Pujol Balcells, J. y Fons Martín, J. L., Los métodos en la enseñanza universitaria, Pamplona, EUNSA, 1978.

Quintero Olivares, G., La enseñanza del derecho en la encrucijada. Derecho académico, docencia universitaria y mundo profesional, Madrid, Cuadernos Civitas, Thomson Reuters, 2010.

Rivera Ayala, L. A., "Cinco competencias genéricas clave en los estudios de derecho”, Revista de Educación y Derecho, n. ${ }^{\circ}$ 11, 2015, 1-19.

Recio RAmírez, M. Á., "El aprendizaje basado en la resolución de problemas: una experiencia práctica”, Docencia y Derecho, n. ${ }^{\circ}$ 7, 2013, 1-8.

SÁnchez Hernández, C., "Método del caso y 'role-playing' en el ámbito del derecho civil", en Mebiela Iglesia, P. et al. (eds.), Presente y futuro de la docencia universitaria, Ourense, Educación, 2016, 477-482. 
Sahuquillo Matero, P. M. y Sarria Chust, B., "La lección magistral participativa", en Gargallo LóPez, B., Enseñanza centrada en el aprendizaje y diseño por competencias en la universidad: fundamentación, procedimientos y evidencias de aplicación e investigación, Valencia, Tirant lo Blanch, 2017, 63-78.

Schuн, J. E., "Bolonia y la enseñanza del derecho", El Cronista del Estado Social y Democrático de Derecho, n. ${ }^{\circ}$ 5, 2009.

Schun, J. E., "Heurística: la chapuza del derecho", en García Amado, J. A., Razonar sobre derechos, Valencia, Tirant lo Blanch, 2016, 333-347.

Torrubia Chalmeta, B., "El aprendizaje práctico del derecho en un espacio virtual", Docencia y Derecho, n. ${ }^{\circ}$ 5, 2012, 1-11.

Tourón, J., Santiago, R. y Díez, A., “The Flipped Classroom”. Cómo convertir la escuela en un espacio de aprendizaje, Barcelona, Digital Text, 2014.

Universidad de Zaragoza, Programa de Mejora e Innovación de la Docencia (En el marco de la Convergencia al Espacio Europeo de Educación Superior), Zaragoza, Instituto de Ciencias de la Educación y vicerrectorados de Ordenación Académica y de Estudiantes, 2004.

Universidad Politécnica de MAdrid, El Método del Caso. Guías rápidas sobre nuevas metodologías, Madrid, Servicio de Innovación Educativa de la Universidad Politécnica de Madrid, 2008.

Universidad Politécnica de Valencia, Método de casos, Valencia, Universidad Politécnica, 2006.

Zurita Martín, I., "La lección magistral”, en SÁnchez González, M. ${ }^{a}$ P. (coord.), Técnicas docentes y sistemas de evaluación en educación superior, Madrid, Narcea, 2010, 17-22.

Zaragoza Martí, M. ${ }^{\text {a }}$ F. y Zaragoza Martí, A., "La docencia invertida y la simulación de juicios como una nueva metodología del aprendizaje jurídico", en RoIGVILA, R., Investigación en docencia universitaria. Diseñando el futuro a partir de la innovación educativa, Barcelona, Octaedro, 2017, 754-764. 